\title{
As lutas na educação física escolar: um ensaio sobre os desafios para sua inserção
}

The fights in scholar physical education: an essay on the challenges for its insertion

DOI: http://dx.doi.org/10.36453/2318-5104.2018.v16.n1.p179

\author{
Gabriela Simone Harnisch, Lizete Wasem Walter, Shayda Muniz de Oliveira Guilherme, \\ Bruna Poliana Silva, Ana Laura Fischer Lottermann, Douglas Roberto Borella
}

Universidade Estadual do Oeste do Paraná (Unioeste)

\begin{abstract}
RESUMO
Trata-se de um ensaio que teve como objetivo discursar acerca dos desafios para a inserção do conteúdo lutas na educação física escolar. As lutas, apesar de contempladas nos documentos norteadores da educação física escolar, ainda carecem de maior atenção, tendo em vista que, muitos empecilhos ainda são elencados para a mesma ser desenvolvida nas escolas. Sendo assim, sugere-se que as lacunas evidenciadas quanto à formação de professores em relação às lutas e a disponibilidade de materiais e espaços sejam sanadas, bem como, que a relação das lutas com a violência seja cada vez menos presente perante a comunidade escolar. Espera-se que este estudo possa suscitar a comunidade acadêmica quanto ao assunto para que tal conteúdo seja desenvolvido, conforme previsto na literatura e nos principais documentos que regulamentam a Educação Física no Brasil.
\end{abstract}

PALAVRAS-CHAVE: Educação Física; Lutas; Escola.

\section{ABSTRACT}

It is an essay aiming to address the challenges for the insertion of content fights in physical education classes. The fights, although contemplated in the guiding documents of physical education classes, still lack more attention, considering that many obstacles are still listed for it to be developed in schools. Therefore, it is suggested that the gaps evidenced regarding teacher training in relation to the fights and the availability of materials and spaces be solved, as well as, that the relationship of fights with violence be less and less present before the school community. It is hoped that this study may stimulate the academic community on the subject so that such content is developed, as predicted in the literature and in the main documents that regulate physical education in Brazil.

KEYWORDS: Physical Education; Fights; School. 


\section{INTRODUÇÃO}

Com o objetivo de proporcionar o acesso à cultura corporal do movimento e/ou às práticas corporais, a Educação Física foi inserida enquanto componente curricular nas escolas regulares brasileiras (BRASIL, 1997). Para que o acesso fosse possível, os Parâmetros Curriculares Nacionais - PCN's sugeriram cinco conteúdos: jogos, esportes, danças, ginásticas e lutas. Recentemente, tais conteúdos foram revistos no mais novo documento norteador da educação brasileira: a Base Nacional Comum Curricular - BNCC, no qual as lutas, foco do presente estudo, permaneceram (BRASIL, 2017).

A prática das lutas é uma atividade tão antiga quanto os jogos, na civilização humana. A partir da arqueologia, encontram-se indícios dos primórdios da humanidade nos mais diferentes cantos do mundo, pinturas em cavernas, paredes, jarros que descrevem a práticas das lutas, essas que por sua vez em cada lugar, praticadas de maneiras distintas umas das outras (ANTUNES, 2016).

Sobre tal conteúdo, justifica-se a importância de sua inserção nas escolas de modo que, além de dar acesso a esta prática corporal, a mesma pode ser um elemento canalizador da violência, podendo melhorar o repertório motor a partir de novos movimentos (BREDA et al., 2010; GOMES, 2008; RUFINO; DARIDO, 2015)

Todavia, muitos professores de Educação Física não desenvolvem o conteúdo lutas. Estes justificam que existem diversos motivos para que isso aconteça, desde a falta de preparo para ministrar tal conteúdo, a associação das modalidades pela sua temática a violência, e mesmo pela ausência de roupas e espaços adequados (BARROS; GABRIEL, 2011; HARNISCH et al., 2017; RUFINO; DARIDO, 2015).

Contrapondo tal discurso, Campos (2014) reflete que trabalhar as lutas é uma oportunidade para discutir acerca da violência, com suas causas, consequências e mecanismos para evitar tal. Ainda, trata-se de uma oportunidade de desenvolver mais uma prática possível na Educação Física Escolar, explorando todos os princípios da corporeidade.

Assim, o objetivo do presente estudo foi de discursar acerca dos desafios para a inserção do conteúdo lutas na Educação Física Escolar. Para alcançar o objetivo proposto, os procedimentos metodológicos pautaramse em um ensaio com base nas principais literaturas e autores do tema.

\section{AS LUTAS NOS DOCUMENTOS NORTEADORES DA EDUCAÇÃO FÍSICA}

Um dos documentos pioneiros na educação física escolar, no que tange os seus conteúdos e as práticas pedagógicas para o seu desenvolvimento, é a obra "Metodologia do ensino de Educação Física", idealizado pelo Coletivo de Autores. Neste, as lutas não estavam contempladas enquanto um único conteúdo, mas a capoeira constava como uma das manifestações da cultura corporal de movimento, juntamente com as ginásticas, danças, jogos e esportes (SOARES et al., 1991).

Neste documento fica clara a importância da capoeira na história do país, quanto ao contexto dos negros no período Brasil escravocrata. Ao longo deste período, a capoeira era desenvolvida em todos os seus sentidos escondidos, camuflados em cada gesto de harmonia do golpe com a música (SOARES et al., 1991).

A Educação Física brasileira precisa, assim, resgatar a capoeira enquanto manifestação cultural, ou seja, trabalhar com a sua historicidade, não desencarná-la do movimento cultural e político que a gerou (SOARES et al, 1991, p.76).

Mais tarde, nos Parâmetros Curriculares Nacionais (PCN, 1997), formularam conteúdos, dentre outras sugestões, que norteassem a Educação Física nas escolas brasileiras. Neste documento, voltado aos ensinos fundamental e médio, os professores deveriam desenvolver jogos, esportes, ginásticas, atividades rítmicas e expressivas, conhecimentos sobre o corpo, bem como, as lutas (BRASIL, 1997).

Deste modo, as lutas foram tratadas enquanto

Disputas em que o(s) oponente(s) deve(m) ser subjugado(s), mediante técnicas e estratégias de desequilíbrio, contusão, imobilização ou exclusão de um determinado espaço na combinação de ações de ataque e defesa. Caracterizam-se por uma regulamentação específica, a fim de punir atitudes de violência e de deslealdade (BRASIL, 1997, p. 37).

Ademais, fica evidente nos PCN's que se tem uma preocupação para com o espaço adequado necessário não somente para a aplicação do conteúdo lutas, mas também para com os demais conteúdos. Porém esse 
desfalque não impossibilita que os professores consigam adaptar os espaços disponíveis para a realização de seu trabalho, um contexto comum até mesmo com os alunos que vivem suas infâncias adaptando minicampos de futebol nas ruas dos bairros onde moram (BRASIL, 1997).

Assim como os demais conteúdos, o conteúdo de lutas deve ser utilizado com a finalidade de desenvolver as capacidades físicas, aprimorar as habilidades motoras, bem como, um material para apreciação dos alunos, de modo que possam expressar suas opiniões quanto a estratégias e atitudes a serem utilizadas em determinadas situações (BRASIL, 1997).

Além disso, Matos et al. (2015) corroboram que as diretrizes curriculares de vários Estados preveem o ensino das Lutas nas aulas de Educação Física, tanto no ensino fundamental quanto no ensino médio.

De forma mais recente, a Base Nacional Comum Curricular - BNCC, o mais novo documento norteador da Educação Física, também contempla as lutas, juntamente com as danças, ginásticas, esportes, brincadeiras e jogos e as práticas corporais de aventura. Neste, cada conteúdo deve ser desenvolvido de acordo com oito dimensões: experimentação, uso e apropriação, fruição, uso e reflexão, construção de valores, análise e compreensão, protagonismo comunitário (BRASIL, 2017).

Quanto ao foco no desenvolvimento do conteúdo lutas, a BNCC

focaliza as disputas corporais, nas quais os participantes empregam técnicas, táticas e estratégias específicas para imobilizar, desequilibrar, atingir ou excluir o oponente de um determinado espaço, combinando ações de ataque e defesa dirigidas ao corpo do adversário. Dessa forma, além das lutas presentes no contexto comunitário e regional, podem ser tratadas lutas brasileiras (capoeira, hukahuka, luta marajoara etc.), bem como lutas de diversos países do mundo (judô, aikido, jiu-jítsu, muay thai, boxe, chinese boxing, esgrima, kendo, etc.) (BRASIL, 2017, p. 176).

Com tais constatações é possível perceber que as lutas, do mesmo modo que os demais conteúdos, devem ser tratadas não somente enquanto uma prática a ser reproduzida, mas também, como um modo de reflexão de sua inserção na comunidade e suas contribuições para outros aspectos da formação humana, que vão além do âmbito físico e motor.

Sendo assim, confirma-se a relevância de trabalhar com o conteúdo lutas, amplamente refletidas nos principais documentos que norteiam a Educação Física Escolar no Brasil. Apesar da, ainda, não obrigatoriedade em seguir as propostas de tais documentos, compreende-se o quanto estes podem contribuir para os professores e, consequentemente, para a formação dos alunos que frequentam as escolas brasileiras.

\section{DESAFIOS PARA A INSERÇÃO DO CONTEÚDO LUTAS NAS AULAS DE EDUCAÇÃo FÍSICA}

Apesar de, conforme explanado anteriormente, as lutas apresentarem grande relevância enquanto conteúdo da Educação Física Escolar, muitos professores ainda não desenvolvem o mesmo devido a diversos empecilhos elucidados pelos mesmos. Dentre estes, destaca-se a relação das lutas com a violência, as lacunas na formação de professores em relação as lutas, a ausência de espaços e materiais e espaços adequados, dentre outros (BARROS; GABRIEL, 2011; BREDA et al., 2010; CAMPOS, 2014; MATOS et al., 2015; RUFINO; DARIDO, 2015).

A inclusão das lutas no currículo real da Educação Física estabelece dependências com a formação dos professores em relação a esse conteúdo (MATOS et al., 2015). Todavia, os professores universitários que ministram essa disciplina na graduação, em sua maioria, tiveram contato com alguma modalidade especifica na condição de praticante. Sendo assim, esse professor restringe suas aulas em apenas uma modalidade, não desenvolvendo o conteúdo de modo que os graduandos possam compreender os aspectos pedagógicos do ensino das lutas de forma global no âmbito escolar (DEL VECCHIO; FRANCHINI, 2006).

Sobre isso, Matos et al. (2015, p. 125) refletem sobre os problemas elencados acerca da formação de professores em relação as lutas, de modo que

As experiências dos professores que colaboraram com esta pesquisa indicam a necessidade de revisão das disciplinas que tratam do conteúdo Lutas nos cursos de Educação Física. O aumento da carga horária ou inclusão de novas disciplinas nos currículos podem contribuir na qualificação dos futuros professores. O ensino tecnicista parece não atender à realidade escolar, ao mesmo tempo os professores reclamam por mais experiências práticas durante a formação inicial, por isso, propostas que não sejam centradas nas técnicas formais mas que, ao mesmo tempo, não negligenciem o fazer corporal presentes nas Lutas possam concorrer para que as Lutas se façam mais presentes no currículo real das escolas. 
Entende-se assim que, para desenvolver este conteúdo no ambiente escolar não é necessário que o professor tenha amplos conhecimentos sobre modalidades especificas de lutas. Mas, que possua os conceitos básicos para sentir-se competente para recriar sua prática e atuar de maneira transformadora (MATOS et al., 2015; RUFINO; DARIDO, 2015).

Para sanar lacunas em relação à formação inicial de professores para o trabalho com o conteúdo lutas, sugere-se que estes busquem a formação continuada, ou seja, o aperfeiçoamento em cursos de extensão universitária, em momentos oferecidos pelas escolas, secretarias de educação ou até mesmo por entidades diretamente ligadas às lutas (BETTI; SO, 2009; CAMPOS, 2014; HARNISCH et al., 2017; MAZINI FILHO et al., 2014; MATOS et al., 2015).

É necessário que os professores de Educação Física participem de cursos de qualificação e aprimoramento da temática "lutas na escola", pois assim poderão agregar mais estratégias técnicas e lúdicas de se abordar o conteúdo, esgueirando-se dos esportes tradicionais, que na maioria das vezes é o olhar principal das aulas de Educação Física (MAZINI FILHO et al., 2014).

Além de dificuldades oriundas da formação inicial deficitária, outro empecilho para o desenvolvimento das lutas na escola é a associação deste conteúdo à violência (BARROS; GABRIEL, 2011). Os participantes da pesquisa de Matos et al. (2015), que relataram não desenvolver tal conteúdo justificaram que a oferta de atividades relacionadas às lutas estimularia atitudes inadequadas para a convivência, como a agressividade.

De modo contrário, na pesquisa realizada por Mazini Filho et al. (2014), nenhum dos professores participantes consideraram as lutas enquanto elemento fomentador de violência e agressividade, sugerindo assim maior conscientização dos professores, por meio de palestras educativas, vídeos específicos e aulas práticas conduzidas de forma que sejam respeitados os oponentes e as regras se fazem necessárias para criações de alunos com um perfil contrário à violência.

Sendo assim, Breda et al. (2010), sugerem que não se permitam agressões relacionadas aos gestos técnicos de modalidades de luta, conforme se observa em filmes e desenhos, mas ensinar os alunos a conviver com a agressividade, não prejudicando-se e nem mesmo, prejudicando aos colegas.

Campos (2014) ressalva que o debate sobre a violência e a agressividade deve ser frequente em aulas de Educação Física, aprimorando questões da concentração, da preservação da integridade física e até do relaxamento, considerando que uma das características importantes das lutas é a paciência.

Outro aspecto importante a ser destacado é a ausência de espaços e materiais adequados. Quanto a isso, as pesquisas de Gomes (2008) e Rufino; Darido (2015), idealizaram propostas pedagógicas para o ensino das lutas a partir do ensino global, e não se focando em modalidades especificas. Para que este ensino fosse possível em ambiente escolar, os autores propõem a utilização de materiais alternativos, como a substituição de tatames por colchonetes; sacos de pancada por bexigas; espadas de metal por jornal, dentre outros. Lopes e Kerr (2015) ainda destacam que a partir dessas práticas pedagógicas não existe a necessidade do professor de Educação Física ser especialista em alguma modalidade de luta para poder ensiná-la.

Ou seja, independente das dificuldades que os professores possam vir a ter para lecionarem as lutas dentro do conteúdo da Educação Física Escolar, estes ainda podem recorrer a inúmeros recursos como vídeos, palestras, atividades lúdicas, aulas de campo de modalidades diversificadas, conhecimento da história de cada modalidade, seus ídolos, regras, países onde são mais difundidas, visitas técnicas dentre outras. Importante enfatizar que o mais importante é a vontade de fazer algo diferente (MAZINI FILHO et al., 2014).

Para tanto, Fabiani, Scaglia e Almeida (2016) ainda sugerem a adoção do jogo de faz de conta enquanto recurso facilitador da aprendizagem das lutas. Desta maneira, segundo os autores,

O professor será um personagem imprescindível no processo de construção e ressignificação dos saberes, tradições, gestos e valores. [...] criando uma teia de significados e conhecimentos que transcenda e ao mesmo tempo se utilize do tradicional, pois a história e a cultura de determinados grupos sociais são essenciais para a apropriação dos saberes referentes à Luta (p. 139).

Sendo assim, destaca-se a importância das lutas como parte da cultura humana, representando um meio eficaz de educação e um conjunto de conteúdos altamente importante para a Educação Física escolar, pois, qualquer que seja a modalidade de luta, exige respeito às regras, a hierarquia e a disciplina, valorizando a preservação da saúde física e mental de seus praticantes. As lutas, assim como os demais conteúdos da Educação Física, devem ser abordadas na escola de forma reflexiva, direcionada a propósitos mais abrangentes do que somente desenvolver capacidades e potencialidades físicas (OLIVEIRA; REIS FILHO, 2013).

Rufino e Darido (2013) à guisa de defender esta ideia da inserção das lutas nas escolas abordam que o 
professor de Educação Física deve ter consigo a compreensão da importância deste conteúdo, já que o mesmo faz parte da cultura corporal, e por esse motivo os alunos devem ser oportunizados a vivenciá-lo, de modo que, com a prática, o professor e o aluno possam aprender e progredir juntos.

\section{CONSIDERAÇÕES FINAIS}

Levando em consideração o objetivo do estudo, argumenta-se o fato de que todos os desafios superados até hoje foi por conta das pessoas, percebendo sua importância, se proporem a enfrentar tal situação. Na Educação Física não foi diferente.

Portanto, quando levado em consideração o conteúdo lutas, que ainda é menosprezado nas escolas, é de extrema importância que o professor de Educação Física se envolva com o mesmo, procurando se aprofundar no assunto, superar as dificuldades de ausência de espaço e vestimenta adequada, bem como da visão do senso comum que retrata as lutas como sinônimo de violência. Assim, envolvendo-se na mudança para uma nova realidade. Realidade esta que, finalmente, atenderá aos documentos que a citam enquanto conteúdo contemplado dentre as práticas corporais a serem desenvolvidas nas aulas de Educação Física Escolar.

Por fim, espera-se que com este estudo novas ideias e propostas pedagógicas para o ensino das lutas no ambiente escolar sejam idealizadas, testadas e amplamente utilizadas por professores de Educação Física, de modo a tornar as lutas cada vez mais disseminadas e compreendidas pela sociedade enquanto manifestação da cultura corporal de movimento.

\section{REFERÊNCIAS}

ANTUNES, M. M. Uma breve reflexão sobre a história e as funcionalidades das artes marciais na contemporaneidade. In: ANTUNES, M. M.; ALMEIDA, J. J. G. Artes marciais, lutas e esportes de combate na perspectiva da educação física: reflexões e possibilidades. Curitiba: CRV, 2016. p. 15-42.

BARROS, A. M.; GABRIEL, R. Z. Lutas. In: DARIDO, S. C. (Org.). Educação física escolar: compartilhando experiências. São Paulo: Phorte, 2011. p. 75-96

BETTI, M.; SO, M. R. Saber ou Fazer? O Ensino de lutas na educação Física Escolar. São Carlos: UFSCAR, 2009

BRASIL. Base Nacional Comum Curricular - Educação é a base. Ministério da Educação, 2017. Disponível em: <http://basenacionalcomum.mec.gov.br/wp-content/uploads/2018/04/BNCC EnsinoMedio embaixa site.pdf> Acessado em: 15 de março de 2018.

BRASIL. Parâmetros Curriculares Nacionais: Educação Física. Brasília: Secretaria de Educação Fundamental, MEC/SEF, 1997. Disponível em: <http://portal.mec.gov.br/seb/arquivos/pdf/livro07. pdf> Acessado em: 10 de marcço de 2018.

BREDA, M.; GALATTI, L.; SCAGLIA, A. J.; PAES, R. R. Pedagogia do esporte aplicada às lutas. São Paulo, Phorte, 2010.

CAMPOS, L. A. S. Metodologia do ensino das lutas na educação física escolar. Várzea Paulista: Fontoura, 2014.

DEL VECCHIO, F. B.; FRANCHINI, E. Lutas, artes marciais e esportes de combate: possibilidades, experiências e abordagens no currículo em educação física. In: SOUZA NETO, S.; HUNGER, D. (Orgs.). Formação profissional em educação física: estudos e pesquisas. Rio Claro: Biblioética, 2006. p. 99109.

FABIANI, D. J. F.; SCAGLIA, A. J.; ALMEIDA, J. J. G. O jogo de faz de conta e o ensino da luta para crianças: criando ambientes de aprendizagem. Pensar a Prática, Goiânia, v. 19, n. 1, p. 130-42, 2016.

GOMES, M. S. P. Procedimentos pedagógicos para o ensino das lutas: contextos e possibilidades. 2008. 119f. Dissertação (Mestrado em Educação Física) - Universidade Estadual de Campinas, Faculdade de Educação Física, Campinas, 2008.

HARNISCH, G. S.; SACHSER, W. F.; GUILHERME, S. M. O.; SILVA, B. P.; RAMOS, A. L. M.; FARIA, J. R. T.; BORELLA, D. R. O conteúdo lutas nas aulas de educação física dos anos finais do ensino 
fundamental. In: Congresso Norte Paranaense de Educação Física Escolar, 2017. Anais... Congresso Norte Paranaense de Educação Física Escolar, Londrina, 2017.

LOPES, R. G. B.; KERR, T. O. O ensino das lutas na educação física escolar: uma experiência no ensino fundamental. Motrivivência, Florianópolis, v. 27, n. 45, p. 262-79, 2015.

MATOS, J.; HIRAMA, L.; GALATTI, L. R.; MONTAGNER, P. C. A presença/ausência do conteúdo lutas na educação física escolar: identificando desafios e propondo sugestões. Conexões, Campinas, v. 13, n. 2, p. 117-35, 2015

MAZINI FILHO, M. L.; SIMÕES, M. R.; VENTURINI, G. R. O.; SAVÓIA, R. P.; MATTOS, D. G.; AIDAR, F. J.; COSTA, S. P. O ensino de lutas nas aulas de educação física escolar. Cinergis, Santa Cruz do Sul, v. 15, n. 4, p. 176-81, 2014.

OLIVEIRA, S. B.; REIS FILHO, A. Ensino de lutas na escola: elemento pedagógico ou estímulo à violência. Lecturas: Educación Física y Deportes, Revista Digital, Buenos Aires, v. 18, n. 180, 2013. Disponível em: <http://www.efdeportes.com/efd180/ensino-de-lutas-na-escola.htm>. Acessado em: 20 de fevereiro de 2018.

RUFINO, L. G.; DARIDO, S. C. Possíveis diálogos entre Educação Física Escolar e o conteúdo das lutas na perspectiva da cultura corporal. Conexões, Campinas, v. 11, n. 1, p. 145-70, 2013.

RUFINO, L. G.; DARIDO, S. C. O ensino das lutas na escola: possibilidades para a educação física. Porto Alegre: Penso, 2015.

SOARES, C. L.; TAFFAREL, C. N. Z.; VARJAL, E.; CASTELLANI FILHO, L.; ESCOBAR, M. O.; BRACHT, V. Metodologia do ensino de educação física. São Paulo: Cortez, 1991.

\section{Autor correspondente: Gabriela Simone Harnisch \\ E-mail: agaby_@hotmail.com}

Recebido: 05 de abril de 2017.

Aceito: 14 de maio de 2018. 